\title{
One Thing You Can Be Sure of: Your Career
}

\section{Will Involve Teamwork}

\section{Judy Geczi}

Saint Louis University, St. Louis, MO

Abstract: Understanding a library's organizational culture is a good first-step in being effective as a new librarian, particularly for someone who is a career-changer.

Author Bio: Judy Geczi is the Business Librarian for the Chaifetz School of Business at Saint Louis University. Judy earned a Master of Business of Administration from the University of North Florida and a Master in Library and Information Studies from the University of North Carolina-Greensboro.

Keywords: librarianship, committees

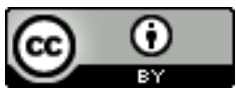

This is an Open Access article distributed under the terms of the Creative Commons Attribution 4.0 International License (http://creativecommons.org/licenses/by/4.0), which permits unrestricted use, distribution, and reproduction in any medium, provided the original work is properly cited. 
Committee work is common in academic libraries. Although the names of these committees vary, many libraries have several committees that successfully assemble people and share ideas. I found that out rather quickly when I started my first full-time job as a new librarian. I was surprised by the number of committees within my library-Web Committee, Marketing Committee, Strategic Planning Committee, and more-and I was told by my manager that I was welcome to join any committee I'd like. The world where I came from prior to becoming a librarian did not have committees, so this option of using formally organized committees to get things done at work was new to me.

Librarianship is my second career. Prior to becoming a librarian, I worked for several years as a computer programmer at a Fortune 500 company. My work environment changed frequently based on a variety of factors, such as company priorities or client needs. Due to my company's culture and how my department operated, I was comfortable with change (as were my co-workers), whether that was a change in the people I worked with, my physical location, or the task at hand. When we started new projects to solve a problem or advance a new idea, a manager selected team members based on desired skillsets for effective and efficient project completion. This was a frequent practice. To have the optimal outcome for any project or task in this environment, it was critical to assemble the right team of people together, so pre-arranged teams or committees did not exist.

Early on in my library career, it became evident that committees were a common tool that librarians use to work together and share ideas or complete tasks. My experiences on library committees have varied. Sometimes new committees with dedicated librarians and staff are formed to tackle a project, which will most likely result in a good outcome. In my current position, I recently started a Data Management and Communication Committee in which I invited members to join, and 
we worked together on a Statistics Report. I was comfortable with this approach in forming a committee because I communicated my vision with potential committee members in advance, providing an option to join or decline. I felt like I had buy-in from the new members, which I knew had been important when working with others in my previous profession. The creation of the report went smoothly, and we were proud of the document we ultimately produced.

Sometimes, new tasks are assigned to a standing library committee to work on and resolve. I have found this to be a much more difficult way to complete projects or tasks. If the committee does not have an effective leader, or has even just one member who is difficult or is not contributing, it takes much more effort to complete the task effectively and in a timely manner. The practice of assigning new tasks to established standing committees is different from the way we organized and divided work in my previous career, and this took some getting used to for me at first.

Conversely, in my experiences working on a new library committee where members share the same vision, I have found that the project is much more likely to run smoothly, and produce a better outcome, similar to the corporate model for project teams. The corporate project team model enables the group to reach their goals faster and more effectively than a standing committee can because each team member's contribution is defined when they are selected for the team, which gives the team members a starting point for action, and capitalizes on people's talents. The one-time teams in my previous profession consistently produced good outcomes. My committee work in libraries has sometimes produced a good outcome, but not always. Many library committees run effectively but libraries still have something to learn from the corporate model of hand-picked project teams for group work. 